\title{
The Impact of Gender and Area of Residence on Adjustment of Retired Old Person
}

\author{
Dr. Bharat H Mimrot*
}

\section{ABSTRACT:}

Age sixty is usually considered the dividing line between middle and old age. Old age is the closing period in the life span. It is a stage when people move away from previous more desirable period to less desirable period. The unfavorable social attitudes towards the elderly are reflected in the way the social group treats them. It is not surprising that many elderly people develop unfavorable self concepts. These tend to be expressed in maladjustive behavior.

The main aim of present research is focused on the comparison of old persons living in the family and in the institution with regard adjustment. On the basis of aim, researcher formulated two hypotheses i.e, the level of adjustment will be higher in retired old persons living in families than institutionalized retired old persons. Second was the adjustment level will be more in retired old males than retired old females. Four hundred retired old persons belong to both the sexes to various families and institutions, of Aurangabad city. Purposive sampling technique was used for the selection. The age group of all respondents was sixty onwards and some factors as like, financial aspects, educational status, fitness, ward less factors will be matched for the sample selection. The old age adjustment inventory was developed by Shamshad Jasbir for data collection. 2*2 factorial research design was applied and two-way ANOVA was used for analysis of data. Results shown that main effect of area of residence is not significant $(\mathrm{F}=0.107$, df-1, 396). Thus Area of residence has no influence on Adjustment and Second main effect nature of gender is significant i.e male and female retired old persons $(\mathrm{F}=106.55$, df-1, 396). Thus gender was influence on adjustment. Hence it concluded that there was no significant difference on adjustment of retired old persons living in Families and institutions and the adjustment level was high in male retired old persons than female retired old persons. Justification and details are given in full-length of paper

Keywords: Adjustment, Retired Old Person

\section{INTRODUCTION}

Adjustment refers to changes in our ways of behaving to meet the changing demands of our environments.

*Asst.Prof. \& Head Dept. of Psychology, NKSPT's Arts, Science \& comm. College, Badnapur, Dist.Jalna, Affiliated to Dr.B.A.M. University, Aurangabad. (M.S), India.

(C) 2014, B Mimrot; licensee IJIP. This is an Open Access Research distributed under the terms of the Creative Commons Attribution License (http://creativecommons.org/licenses/by/2.0), which permits unrestricted use, distribution, and reproduction in any Medium, provided the original work is properly cited. 


\section{The Impact of Gender and Area of Residence on Adjustment of retired old person}

Obviously, Adjustment can be defined as a person's interaction with his environment. Each person constantly strives to meet his needs and reach his goals. At the same time he is under pressure from the environment to behave in certain ways. Adjustment involves the reconciliation of personal and environmental demands. Interaction means mutual bearing or influence. Every person is influenced by these surroundings. And each has same effect on the particular environmental settings of which he is a part. The relative amount of influence varies from setting to setting and from time to time within a particular setting. Sometimes an individual is more influenced than influential, and sometimes it is the other way around.

Environment refers to everything external to the person with which he is in some relation. In the study of adjustment, the unit of study is frequently a social group. For example, the individual is studied in relation to his family or to the people with whom he work.

\section{Criteria's of Good Adjustment}

Jahoda (1958) who found that many ideas in this area could be sorted in to a number of categories. Nine major categories are utilized in the materials which follow, but the sorting job is for from perfect. Some categories overlap and some ideas cut across categories and make several appearances. Even so the material offers the substance of present thinking concerning desirable human qualities. A good deal has been written about the personal qualities or patterns of behavior which are desirable in human beings. Many lists of these qualities have been drawn.

1. Happiness 2. Harmony 3. Self Regard 4.Self Concepts 5. The Subjective Self 6. The Social Self 7. The Ideal Self 8. Self Qualities 9. Self Insight 10. Self Identity 11. Self Acceptance 12. Self Esteem 13. Self Disclosure 14. Personal Growth 15. Personal Maturity 16. Personal Integration 17. Contact with the Environment 18. Effectiveness in the Environment

\section{Types of Adjustment}

Human beings with few exceptions, live among other human beings. They live in groupsin family, neighborhood, and community groups, in school and job groups, and so on. We sometimes speak of "personal adjustment" almost as if it could be considered apart from the social environment. But as has been indicated, the idea of adjustment implies an interaction between the individual and his surroundings, he doesn't just adjust, he adjusts to something, or, to put it in another way, he interacts with it.

\section{Family Adjustment}

Of all areas of adjustment none is more important than the family. Much of our existence is spent in the family settings the family we Greco up in and the family we have established or

will establish for ourselves. The consequences of family experiences are reflected in every facet of our lives. Families are complex and changing. Each family has a life of its own. It born it 


\section{The Impact of Gender and Area of Residence on Adjustment of retired old person}

lives, and it dies. The membership changes, each member changes, and the interaction between members changes. There have been relatively few longitudinal studies of families. The information from several studies suggests that there are systematic variations in a family's interaction over the year but the evidence is still too scant to warrant conclusions. (Yarrow \& Yarrow, 1964). One way of defining family adjustment is in terns of physical coherence. Does the family stay together? Does it continue to exist as a physical entity? This as a simple definition, one that states an essential that can be easily and objectively determined. On the other hand, the essential it states is a minimum one, \& most of us would reserve the term "adjusted" for families who do mush more than simply cohere. A second definition of family adjustment is in terms of happiness. Many of us equate adjustment with happiness, and we may think of the well adjusted family as one which is happy or has a general sense of well being. The limitations of this approach to a definition are inherent in the subjective nature of happiness and in the considerable variation in happiness among family members and in any member from time to lime. A third definition is in terms of task achievement. There are certain tasks which a family is expected to perform. For example, it is expected to contribute to the support \& socialization of its members, by this definition, the well adjusted family is one which achieves the tasks the society has set for it.

\section{School Adjustment}

Much of our early life is spent in school, "taught to the tune of a hickory stick" or any other way, our school experiences have a easting effect. Like families, schools are complex and changing environments. Each school system involves many people \& forces-pupils, teachers, guidance workers or counselors, curriculum specialists, principals, committees, boards, and other supervisory personnel, parent groups, teacher groups, parent teacher groups as well as many other groups and individuals.

What is meant by good adjustment as applied to a child's school life? One common way of defining school adjustment is to equate it with academic achievement. In this approach, the student who achieve what he is expected to achieve is considered adjusted. The student who does not learn, who is held back in grade, or who drops out of school before graduation would not meet this criterion of adjustment. A second way of defining school adjustment is in terms of the relationships a child forms with his teachers \& fellow students. By this definition, a child who gets along with his classmates \& his teachers is considered adjusted. A child who is unable to form satisfactory relationships-one who is perhaps aggressive and unruly or overly shy and withdrawing would be considered poorly adjusted.

\section{College Adjustment}

College is a high point in our lives- we look forward to it, enjoy it. \& carry pleasant memories along with us when we graduate. But many students find their college year filled with anxiety, doubt and struggle. Some drop out along the way. College environment \& college 


\section{The Impact of Gender and Area of Residence on Adjustment of retired old person}

populations vary considerably from institution to institution students who do poorly in one college environment may do better in another. Even within a campus different programs may present very different demands. What is meant by good college adjustment? One way defining college adjustment is simply as academic achievement, in this approach, the adjusted student is one who makes adequate grades, passes his courses and graduates. Conversely the maladjusted student is one whose grades are unsatisfactory whose course work is marginal, or falling, and who drops out of school before graduation.

\section{Vocational Adjustment}

For many of us, work is more than a way to earn a living. It as a way of living. We pattern our lives around our work, and we look to our work to add pattern and meaning to our lives (Super. 1957). Our work may be the most important source of our identity. The question, who is he? Is frequently assumed to mean, what does he do? We ask, who is he? And the answer comes, he is a teacher, or he is in sales work, or he works in the shipping department down at the plant, knowing what a man's work is enables one to make some guesses about his educational background, his economic social \& intellectual status \& beyond this, his attitudes, values, and style of living (Wren 1964). What is good vocational adjustment? One way of defining vocational adjustment is in terms of vocational maturity. A person is said to be vocationally maturity. A person is said to be vocationally mature if his vocational behavior is appropriate to his chronological age, that is, if it has reached the level of development, generally characteristic of his age peer. If vocational behavior is less fully developed than age warrants, he is considered vocationally immature or maladjusted. If vocational behavior is more advanced than is expected. He is considered precocious (just as he would be if his physical, intellectual, or social behavior showed accelerated development).

\section{Marital Adjustment}

Marriage has been much written about and much studied. Courses in marriage \& family living, marriage manuals, and marriage counselors abound, in our culture. It is difficult to reach marriageable age without being aware of some of the pitfalls of marriage. Nevertheless marriage continues in a troubled area. Attention is continually called, to the high divorce rate. About three out of every ten marriage wind up in the divorce courts. Probably everyone knows of marriages which have failed. Many of the marriages which do survive their stormy weather, in some marriages, the first few years are particularly touch \& go. Other marriages run into stress at the time the first child is born, an event which changes the interaction of the house hold in crucial ways. It is not uncommon to see a marriage disintegrate with the passing years the spouses develop in different directions \& interact less \& less. What is good marriage adjustment? What is poor marriage adjustment? Two commonly used definitions are implied in what was just said; one involves the idea of permanence the other, happiness. 


\section{The Impact of Gender and Area of Residence on Adjustment of retired old person}

\section{REVIEWS:}

Agren Margarita (1998) used depth interviews to investigate how life is experienced by persons at age $\mathbf{8 5}(n=129)$ and again at $92(n=41)$. Seven patterns of adjustment ranging from self realization to withdrawal emerged and heterogeneity remained at follow up with some changes in the characteristics of the categories and in coping strategies. Beal(2006), Older women report more loneliness than male peers. Loneliness is an area of concern related to the well being of older women because it is a cause of emotional distress and is linked to a variety of health problems in older individuals. Life changes, including widowhood and relocation, are associated with increased vulnerability to loneliness. Gender, social, and cultural factors influence the experience of loneliness in older women. Cognitive and interactionist theoretical approaches to loneliness have utility for nursing practice and research with older women who experience loneliness. Golant and Stephen M(1984) suggested that gerontologists have shown particular interest in whether old people's morale or life satisfaction is influenced by the quality of their residential environment. The extent to which older persons' assessments of their lives are influenced by their place of residence was examined through structured interviews with a random sample of 400 persons aged 60 and older, living in a middle class urban community. Subjects completed the Life Satisfaction Index A and measures assessing personality characteristics, demographic variables, socioeconomic status, life stage, activity patterns, and environmental experiences. The results revealed statistically significant direct effects of nine social and physical environment experiences on older people's life satisfaction. In addition, nine individual variables were found to independently influence life satisfaction. The individual differences and environmental experiences together explained nearly half of the statistical variation in the older people's life satisfaction levels. Hull, Kathleen V. (1990) found that, within the next 40 years, people age 65 and over will comprise $20 \%$ of the population, yet problems facing this older generation and their families are just coming to the attention of researchers and the public. Accordingly, this literature review focuses on the special needs of older adults and their families. After an introductory overview, the paper first reviews studies on adjustment to retirement, addressing issues such as cultural stereotypes, sex differences in adjustment, factors influencing survival rates, successful approaches to post-retirement job seeking, and marital well-being after retirement. The second part of the paper reviews research on social support networks among the elderly, including spouses, children, friends, and hired caregivers. The third section reviews studies of issues related to coping with the death of a spouse, role loss and other stressful transitions common to older adults. The fourth section addresses research on the availability and use of educational opportunities by the aged. The fifth section covers research on the correlates of life satisfaction among the elderly. These include educational level, health, income, marital satisfaction, and relationships with children. The final section reviews studies of leisure activities among older adults, including studies of what motivates older adults to pursue various kinds of leisure activities and the beneficial effects of such activities on life satisfaction. Carr, Deborah (2004) examined how pre-loss emotional and instrumental dependence on one's spouse affects older adults psychological adjustment to 
widowhood. Analyses are based on 297 persons from the Changing Lives of Older Couples [CLOC study], a prospective study of widowhood among adults aged 65 and older. Women who were most emotionally dependent on their spouses had the poorest self esteem while still married, yet evidence the highest levels of self esteem following loss. Men who were most dependent on their wives for home maintenance and financial management tasks experience the greatest personal growth following loss. These results suggest that widowed persons who were once highly dependent upon their spouses reap psychological rewards from the recognition that they are capable of managing on their own. Hass-Hawkings Gwen(1980) shown that, Although widowhood is a disruptive and inevitable phenomenon for many older people, few studies have explored either adjustment to widowhood or the impact of widowhood on the lives of elderly people. Recently widowed persons $(\mathrm{N}=51)$, ranging in age from 49 to 83 years old, were interviewed to examine their relatively immediate psychosocial adjustment to widowhood. The time interval between death of spouse and the interview ranged from 4 to 12 weeks. No correlation was found between the Social Network Scale and any of the four adjustment measures, suggesting that the existence of a social network characterized by stability, intimacy, and reciprocity was not an important factor in the adjustment of these recently widowed persons. Positive correlations were found between preparation for loss and self-reports of adjustment, and between internal control and life satisfaction; negative correlations were found between internal control and psychiatric symptoms, and depression. Loneliness was the most frequently reported problem of widowhood, perhaps indicating that loneliness prior to widowhood may be a significant contributing factor to post-widowhood adjustment. Compared to samples of other older people, these subjects were relatively well-adjusted as indicated by scores on functional health, depression, and life satisfaction scales.

PROBLEM:- "Comparative study of adjustment among retired old persons living in family and Institution."

\section{OBJECTIVES:}

1) To compare the level of adjustment of retired old persons living in family and Institution.

2) To find out Gender differences of adjustment in retired old persons.

\section{HYPOTHESES:}

1) The level of adjustment will be higher in retired old persons living in families than institutionalized retired old persons.

2) The adjustment level will be more in retired old males than retired old females. 


\section{METHODOLOGY:}

\section{Sample:}

The sample of the present study consists of 400 old persons. These 400 retired old persons belong to both the sexes to various families and institutions, of Aurangabad city. Purposive sampling technique will be used for the selection. The age group of all respondents will be sixty onwards and some factors as like, financial aspects, educational status, fitness, ward less factors will be matched for the sample selection. An index of gender wise break up the ss is shown from the following table:-

\begin{tabular}{|l|l|l|l|}
\hline Gender & $\begin{array}{l}\text { Retired old persons } \\
\text { living in family }\end{array}$ & $\begin{array}{l}\text { old persons living } \\
\text { institution }\end{array}$ & Total \\
\hline Male & 100 & 100 & 200 \\
\hline Female & 100 & 100 & 200 \\
\hline Total & 200 & 200 & 400 \\
\hline
\end{tabular}

\section{Operational definition of the terms used in the sample:-}

\section{1) Retired old person living in the family:-}

Old people who are more than sixty age and living in the family.

\section{2) Old people living in institution:-}

Old people who are more than sixty (60) age and who are living in the institution.

\section{Variables under the Study:}

The following various are involved in the research.

1) Areas of residence (IVs):- A) Livening in institutions retired old person B) Living in families retired old person.

2) Gender:- A) Male B) Female

2) Research Concepts (DVs) :-Adjustment

\section{$2 \times 2$ factorial designs:}

\begin{tabular}{|l|l|l|}
\hline \multirow{2}{*}{ Gendar (B) } & Area of residence (A) \\
\cline { 2 - 3 } & Living in family(A1) & Living in institution(A2) \\
\hline Male (B1) & A1B1 & A2B1 \\
\hline Female (B2) & A1B2 & A2B2 \\
\hline
\end{tabular}

Tools for data collection: - Adjustment inventory by shamshad Jasbir 
The old age adjustment inventory was developed by Shamshad Jasbir on a sample of old aged male for female population of Bihar ranging between 50-65 years of age belonging to different categories and these on the verge of retirement. Those already retired and those who are in active service.

\section{Reliability:}

The test retest reliability of the test (area wise and overall adjustment scores) have been presented in below table.

Test -retest co-efficient of correlation of old age adjustment inventory $(N=100)$

\begin{tabular}{|l|l|l|}
\hline Area of adjustment & Co-efficient of correlations & P value \\
\hline Health & 0.96 & $<.01$ \\
\hline Home & 0.93 & $<.01$ \\
\hline Social & 0.94 & $<.01$ \\
\hline Marital & 0.95 & $<.01$ \\
\hline Emotional & 0.92 & $<.01$ \\
\hline Financial & 0.91 & $<.01$ \\
\hline Total & 0.93 & $<.01$ \\
\hline
\end{tabular}

Validity: On the whole, it gathered that the newly developed adjustment inventory has high validity.

\section{Scoring:-}

The keyed response is to be assigned one score. The keyed response is some were in terms of 'yes' and some were in the form of 'No' response to the undecided category is not to be given any score on score is to be given to the response in the direction of adjustment and $\mathrm{O}$ (Zero) to the response in the directions of maladjustment. Hence the higher score indicates better adjustments the response are scored area wise the sum of score in different areas provide measure of overall adjustment.

\section{Procedure of data collection:-}

For administering the scales the Ss were called in small groups. Their seating arrangement was made in the recreation hall of the institutions. All the scales used in the study were group scales; hence they were administered on small groups of subject. Selected numbers of the Ss were asked to assemble in the recreation hall. At a time only 15 to 20 Ss were invited. They were asked to sit in chairs kept at sufficient distance from each other, for the reason than one cannot see what the other had written in the answer sheet. Researcher explained the purpose of the study in brief. Through informal talk rapport was established and the Ss were requested to 
answer the items of their scales sincerely \& honestly. They were assured that their responses would be used strictly for research purpose only, and would not be disclosed to others. Their written documents would be treated as confidential. The sets of Adjustment inventory was distributed among them. They were asked to fill in the information about themselves on the front page. Afterwards they were asked to read the printed instructions along with the investigator. There are some questions given here. You have to answer each question. Each question is provided with alternatives "yes" "No" \& very often, sometime, Never. You have to select one of these three alternatives as your answer to the question. However you have to select only that alternative which you think, is most appropriate in your case. You select your remark \& put a $\sqrt{ }$ mark on the answer that you select. I assure you that your responses will be treated as confidential. The procedure was demonstrated to the Ss. Doubts \& difficulties raised by the Ss were answered to their satisfaction. There was no time limit, however. The Ss were told to write the responses as fast as they can. Filled copies of the scales were collected only after verifying that the Ss had replied each question. The Ss were given sufficient time to write the responses to the statements. Filled copies of the scales were collected at the end carefully, it was seen that the Ss had answered each and every statement. The first session of data collection was concluded.

\section{Statistical Analysis:-}

The data were carefully scrutinized separately for four main groups as well as for the entire sample by employing frequency distributions and descriptive statistics, Means, and Standard Deviations are reported for Adjustment. The above statistics are reported for old persons as well as for the entire sample. To evaluate Person wise differences in the various variables employed in this research, Two-way analysis of variance (ANOVA) have been carried out with family life and gender as the independent variables and Adjustment as the dependent variables.

Table No.1: shows descriptive statistics for the dependent variable Adjustment:-

\begin{tabular}{|l|l|l|l|l|}
\hline Variable & Area of living & $\mathrm{N}$ & $\begin{array}{l}\text { Mea } \\
\mathrm{n}\end{array}$ & Std. Deviation \\
\hline \multirow{5}{*}{$\begin{array}{l}\text { Adjustme } \\
\text { nt }\end{array}$} & $\begin{array}{l}\text { Retired old persons living in } \\
\text { Families }\end{array}$ & 200 & $\begin{array}{l}85.7 \\
0\end{array}$ & 7.99 \\
\cline { 2 - 6 } & $\begin{array}{l}\text { Retired old persons living in } \\
\text { Institutions }\end{array}$ & 200 & $\begin{array}{l}85.5 \\
0\end{array}$ & 6.34 \\
\cline { 2 - 6 } & Gender & & \multicolumn{3}{|l}{} \\
\cline { 2 - 6 } & Male Retired old persons & 200 & $\begin{array}{l}88.8 \\
4\end{array}$ & 6.64 \\
\cline { 2 - 6 } & Female Retired old persons & 200 & $\begin{array}{l}82.3 \\
6\end{array}$ & 6.24 \\
\hline
\end{tabular}


Above descriptive statistical table shows Mean \& SD of Retired old persons living in Families and Institutions as well as male and female Retired old persons. Mean of Retired old persons living in families is 85.70 and its SD is 7.99; Mean of Retired old person living in Institutions is 85.50 and its SD is 6.34. The Mean of Male Retired old persons is 88.84 and its $\mathrm{SD}$ is 6.64; Mean of female Retired old persons is 82.36 and its SD is 6.24.

Table No.2: Two-way multivariate analysis of variance for dependent variable Adjustment.

\begin{tabular}{|l|l|l|l|l|l|}
\hline Source & Sum of Squares & df & $\begin{array}{l}\text { Mean } \\
\text { Square }\end{array}$ & F & Sig. \\
\hline Area of Living & 4.203 & 1 & 4.203 & 0.107 & NS \\
\hline Gender & 4192.563 & 1 & 4192.563 & 106.55 & .001 \\
\hline $\begin{array}{l}\text { Area of Living X } \\
\text { Gender }\end{array}$ & 957.903 & 1 & 957.903 & 24.345 & .001 \\
\hline Error & 15581.130 & 396 & 39.346 & & \\
\hline Total & 2951851.000 & 400 & & & \\
\hline
\end{tabular}

p- $0.05=3.86 \quad 0.01=6.70$

In the above table two-way multivariate analysis of variance, it is shown that the first main effect of area of Living i.e Institutions and families the F Value is (df1,396) $=0.107$, which is not significant at any level. Hence it indicates that Retired old persons living Institutions and families show the no significant difference on Adjustment.

Second main effect is nature of gender i.e male and female Retired old persons the $\mathrm{F}(\mathrm{df}=1,396)$ value is 106.55 . Which is significant at 0.01 level. Hence Retired old male and female person's show significant difference on Adjustment.

The interaction effect shows significant difference on Adjustment, " $F "$ value is 24.345.which is significant at 0.01 level.

For the critical analysis, researcher analyzed Post-Hoc test as " $t$ " test. 
Table No.3: Showing difference between Retired old persons living in Families and Institutions.

\begin{tabular}{|c|c|c|c|c|c|}
\hline $\begin{array}{l}\text { Area } \\
\text { living }\end{array}$ & $\mathrm{N}$ & Mean & SD & $\mathrm{t}$ & $\begin{array}{l}\text { Significance } \\
\text { level }\end{array}$ \\
\hline $\begin{array}{ll}\text { Retired } & \text { old } \\
\text { persons } & \\
\text { living } & \text { in } \\
\text { Families } & \\
\end{array}$ & 200 & 85.70 & 7.99 & \multirow{2}{*}{0.284} & \multirow{2}{*}{ NS } \\
\hline $\begin{array}{l}\text { Retired old } \\
\text { persons } \\
\text { living in } \\
\text { Institutions }\end{array}$ & 200 & 85.50 & 6.34 & & \\
\hline
\end{tabular}

In the above table the mean value of Retired old persons living in Families is 85.70.and SD is 7.99 as well as the mean value of Retired old persons living in Institutions is 85.50 and SD is 6.34. The obtained $\mathrm{t}$ value is 0.284 , which is not significant. On the basis of mean it is concluded that there is no significant difference between Retired old persons living in Families and Institutions, "the level of adjustment would be higher in retired old persons living in families than Institutionalized retired old persons". This hypothesis is rejected.

\section{Graph-1}

Following graph shows adjustment of retired old persons living in families and Institutionalized retired old persons.

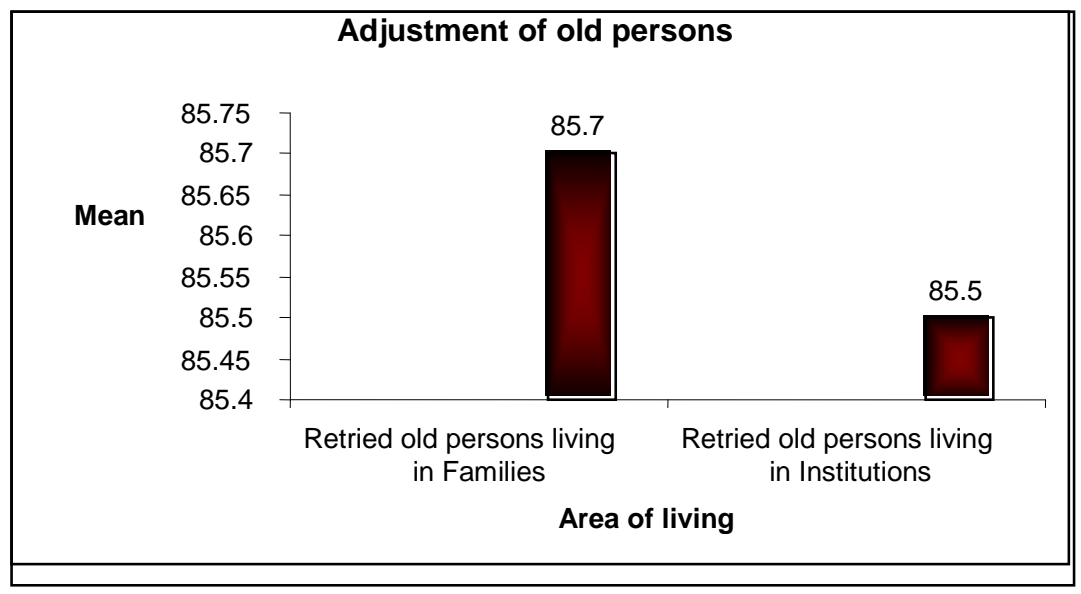

The above graph shows that the mean value of Adjustment of retired old persons living in families and Institutions. It shows that there is no mean difference of retired old persons living in 
families and Institutions.

Table No.4: Showing difference between Male and female Retired old person on dependent variable adjustment.

\begin{tabular}{|l|l|l|l|l|l|}
\hline Gender & $\mathrm{N}$ & Mean & $\mathrm{SD}$ & $\mathrm{t}$ & $\begin{array}{l}\text { Significance } \\
\text { level }\end{array}$ \\
\cline { 1 - 4 } Male Retired old persons & 200 & 88.84 & 6.64 & \multirow{2}{*}{10.043} & 0.01 \\
\cline { 1 - 4 } Female Retired old persons & 200 & 82.36 & 6.24 & & \\
\hline
\end{tabular}

In the above table the mean value of male Retired old persons is 88.84 and SD is 6.24 as well as the mean value of female Retired old persons is 82.36 and SD is 6.24. The obtained $t$ value is 10.043 , which is significant at 0.01 level. Hence, it is concluded that there is higher level of adjustment in male Retired old persons. So second hypothesis the adjustment level would be more in retired males than retired females, is accepted.

Graph-2 Following graph shows adjustment of male and female Retired person.

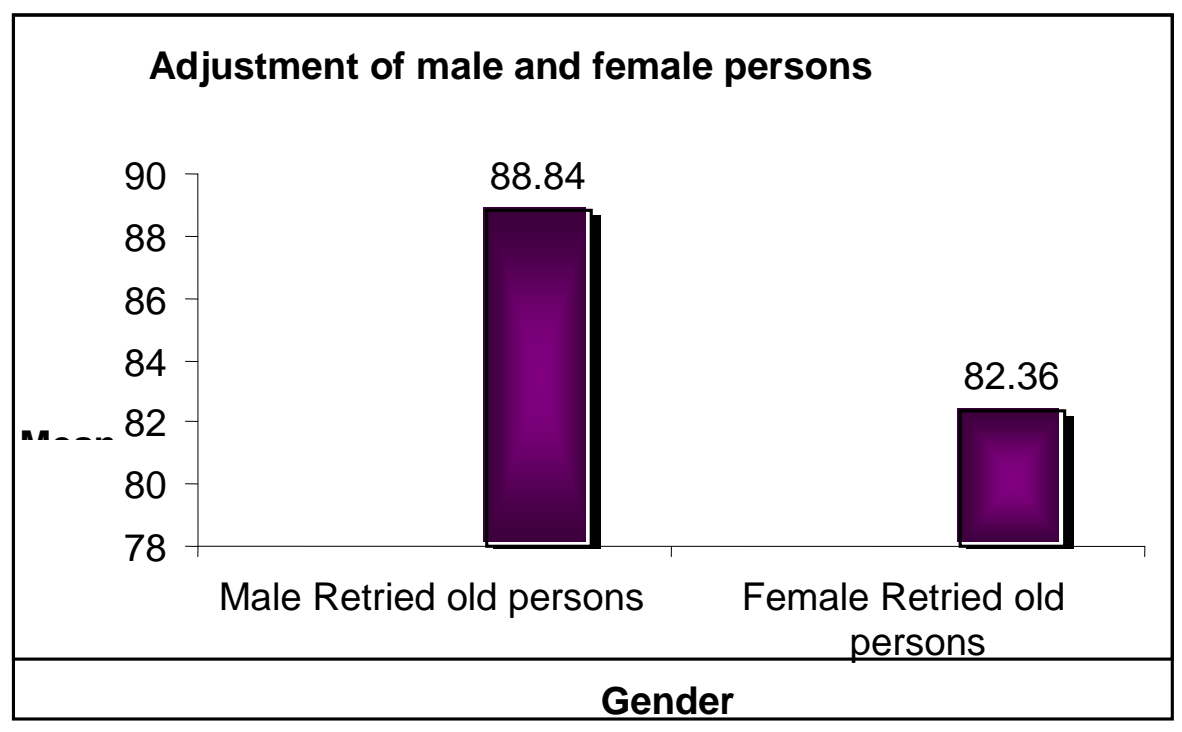

The above graph shows the mean value of adjustment of male and female Retired old person. The male Retired old persons mean is higher than female Retired old persons; hence the adjustment level is more in male's Retired old persons. 


\section{The Impact of Gender and Area of Residence on Adjustment of retired old person}

Hypotheses No. 1:- The level of adjustment would be higher in retired old persons living in families than institutionalized retired old persons.

Table No. 1, 2 and 3 indicate mean values of adjustment, ' $F$ ' values and ' $t$ ' values. The means of adjustment score are 85.70 and 85.50 respectively for retired old persons living in families and institution. The main effect of area of residence is not significant $(\mathrm{F}=0.107$, df1, 396). Thus Area of residence has no influence on Adjustment. And ' $t$ ' values is $0.284>0.05$. Thus there is a no significant difference on adjustment of retired old persons living in families and institutionalized retired old persons. The results did not support the hypothesis stating that "The level of adjustment would be higher in retired old persons living in families than institutionalized retired old persons". Hence it is concluded that there is no significant difference on adjustment between retired old persons living in Families and institutions. It indicates that they get same experience after the retired life.

In connection with the above cited findings 'Adjustment in old age may often be difficult for individuals, as it requires adopting a new life style, characterized by decreased income and activity and increased free time (Streib \& Schreider 1971; McGee et.al., 1979; National Council on Aging [NCA], 1981'. The term adjustment in gerontological literature is tantamount to internal and external equilibrium of the human being (Rosow, 1967). On the other hand, George (1980) states that adjustment of an individual involves two conditions: First, the individual attempts to meet the demands of the environment; and second, the individual perceives and experiences a sense of general well-being in relation to the environment. The concept of adjustment has also been studied from the practical or empirical perspective and Donahue et al., (1960) have cited the following factors, such as satisfactory health, married life, good families relationship, friendship, feeling of security, social status equal to that of what they have had previously and plan for the future, religiosity, and belief in rebirth to be positively associated with good adjustment in old age. Raghani and Singhi (1970) studied the "adjustment problems of retired persons". They reviewed a number of empirical studies to examine the factors associated with successful adjustment in old age and pointed out a number of weaknesses with regard to good and poor adjustment. They argued that firstly, there is a lot of cultural and socio-economic variation among respondents; and secondly, the effect of retirement upon individuals should be studied prior to determining and establishing characteristics of good and bad adjustment.

Retirement is different today. In the past, it meant a slowing down of activity and the completion of work life. Retirement was generally used in reference to men. Now retirement for both men and women can mean having the opportunity to take up hobbies, travel, start a new career, go back to school, spend time with families, take care of grandchildren, or work only part-time.

After retirement begins, time spent with colleagues from work diminishes, while opportunities to spend more time alone, or with a spouse, families, or friends, increases. Reactions to these relationship changes can be different for each person. Some may enjoy the 


\section{The Impact of Gender and Area of Residence on Adjustment of retired old person}

wonderful opportunities for sharing additional experiences with a spouse, families, or friends. For others, this increased time together can create a strange and unfamiliar situation particularly for a spouse who has been a full time homemaker and then suddenly having a retired spouse at home each day. Additional challenges can arise in a partnership in which one spouse wants to continue working while the other spouse is ready for a more leisure-filled retirement. This may give rise to families' tensions, especially during the initial transition period. The key is to remain aware that changes in relationships are a normal and expected part of retirement.

Retirement is a personal experience; some find adjusting to it easier than others. Making a smooth transition to retirement depends on financial circumstances, health, and attitude, as well as the reaction and behavior of loved ones and friends. Most everyone faces the following challenges Using the newly found available time that retirement brings to develop new interests and skills, retirees can acquire new roles, such as volunteer, artist, gardener, traveler, or student to name just a few. The emotional reactions to leaving behind prior roles and taking on new ones can range from shock, fear, and nervousness to excitement, joy, and relief.

\section{Hypothesis No.2:- The adjustment level will be more in retired old males than retired old females.}

Table No. 1, 2 and 4 indicate mean values of adjustment, ' $F$ ' values and 't' values. Means of adjustment score are 88.84 and 82.36 respectively for male and female retired old persons. Second main effect nature of gender is significant i.e male and female retired old persons. $(\mathrm{F}=$ 106.55, df-1, $396 \mathrm{P}<0.01$ ) and't' values $10.04<0.01$. Thus type of gender has influence on Adjustment. The mean of adjustment is higher in male retired old persons than female retired old persons. These results support hypothesis No. 2 stating that "The adjustment level would be more in retired old males than retired old females."

Results of the present study are consistent with finding of Carr, Deborah (2004) and HaasHawkings, Gwen-(1980) suggested that the low level of adjustment in widowhood women. In one study conducted by Crandall (1980) who found that individuals who live with their spouse were happier and better adjusted. Being married with a living spouse is an important source of support for a retired woman which leads to better adjustment. Discontinuity in marital status, separated or widowed seemed to have disruptive consequences and negative effects on the adjustment of retired women. The findings that retired widows were the least adjusted as compared to those with spouse or separated were in line with findings of Holmes and Rahe (1976), who found that the death of a spouse was a major life stressor requiring more adjustment than any other life event Jamuna and Ramamurti (1988) also found that widows were poorly adjusted as compared to non widows. Following widowhood there was usually a sudden loss of financial support and a consequent by a lowering of the standard of living. Hull, Kathleen V (1990) studied on adjustment to retirement, addressing issues such as cultural stereotypes, sex differences in adjustment, factors influencing survival rates, successful approaches to postretirement job seeking, and marital well-being after retirement and found that women are facing much more adjustment problem. Another study shows V. A. BraithwaiteD. M. Gibson and 
Richard Bosly-Craft (1986) that female retirees identify four poor adjustment styles-poor health, negativism, change adaptation and retirement reluctance.

CONCLUSIONS:- On the basis of data and discussion of results, the hypotheses were tested and following conclusion were drawn:

1. There was no significant difference on adjustment of retired old persons living in Families and institutions.

2. The adjustment level was high in male retired old persons than female retired old persons.

\section{REFERENCES:-}

1. AE Korten, AF Jorm, Z Jiao, L Letenneur, PA Jacomb(2007): Health, cognitive, and psychosocial factors as predictors of mortality in an elderly community sample: Journal of Epidemiology and Community Health, Vol 53, 83-88.

2. Agren. Margaret. (1998), "Life at 85: A Qualitative Longitudinal Study" International Journal of Aging \& Human Development, Vol. 47, (2), 105-117.

3. Allport, G.W. (1958), Personality. New York: Henry Holt.

4. Allport, G.W. (1961), Pattern \& Growth in Personality. New York: Holt.

5. Beal C.(2006): Loneliness in older women: a review of the literature: Issues Mental Health Nursing, vol 27(7):795-813.

6. Carr, Deborah (2004), "Gender, Pre-loss Marital Dependence, \& Older Adults Adjustment to Widowhood" Journal of Marriage and to Family, Vol. 66, (1), 220-235.

7. Donohue, W., Hunter, W., and Coons, D.( 1953): A study of the socialization of older people, Geriatrics, 8:656-666, Dec.

8. Golant, Stephen M. (1984):The Influence of the Experienced Residential Environment on Old People's Life Satisfaction: Journals of ageing, 1984-11-18.

9. Haas - Hawking, Gwen \& Other (1980), An Exploratory Study of Adjustment to Widowhood Journal of Personality and Social Psychology, Vol. 52

10. Hull, Kathleen V. (1990): Special Problems of the Elderly. (ED327758); Online Dissertations/Theses.

11. Streib, G. F. (1958) Situational determinants: Health and economic deprivation in retirement: Journal of Social Issues, vol. 14 pp.33.

12. Super, D.E.(1957), The Psychology of Careers. New York: Harper \& Row.

13. V. A. Braithwaite, D. M. Gibson and Richard Bosly-Craft(1986), An exploratory study of poor adjustment styles among retirees. Social Science \& Medicine, Volume 23, Issue 5, 1986, Pages 493-499.

14. Wren,C.G. (1964), Human values and work American life. In H. Borrow (Ed) Man in a World at Work Boston: Houghton Mifftin. 24-44.

15. Yarrow, L.J. \& Yarrow, M.R. Personality continuity and change in the family context. In P. Worchel \& D. Byrne (Eds) . Personality Change. New York: Wiley. 